\title{
APPLICATION OF AN INTEGRATED AND SELF- CONTAINED ELECTROMAGNETIC ACOUSTIC RECORDER FOR MONITORING THE ROCK MASS STRUCTURE AND DEVELOPMENT OF GEODYNAMIC PROCESSES IN ORE MINES
}

\author{
Anatoly Bespal'ko*, Ludmila Yavorovich, Pavel Fedotov, Evgeny Pomishin and \\ Maksim Vedyashkin \\ Tomsk Polytechnic University, Institute of Non-Destructive Testing, 634050 Tomsk, Russia
}

\begin{abstract}
The paper presents a block diagram of the recorder of electromagnetic and acoustic signals. The recorder provides monitoring of electromagnetic and acoustic signals under changing stress-strain state of heterogeneous materials and rocks. The analog amplifier input sensitivity of electromagnetic signals in 4 channels is $10 \mu \mathrm{V}$, that of the electromagnetic signal intensity is $10 \mu \mathrm{V}$ and that of acoustic signals is 50 $\mu \mathrm{V}$. The operating frequency range of recording is $(1 \div 100) \mathrm{kHz}$. The averaging of electromagnetic and acoustic signal amplitudes is performed within 1 or 5 seconds. The data on electromagnetic and acoustic emission materials is recorded in digital format in the internal memory of the recorder. The recorder operates off-line within 7 days. Repeated testing of the recorder in natural conditions of the Tashtagol mine showed that the changes in the amplitude and frequency parameters of electromagnetic signals (EMC) indicate the structural damage in mines made of rocks which differ in their electrical properties. Measurements of the intensity of electromagnetic signals enable monitoring the changes in the stress-strain state of rocks during and after blasting and other geodynamic phenomena.
\end{abstract}

\section{Introduction}

Electromagnetic radiation (EMR) occurring in the rocks under mechanical impact has been studied for many years in many countries around the world [1-7]. The key motive of these studies is high potential of EMR to be used for predicting geodynamic events such as earthquakes, rock bursts, landslides and others. Mathematical modeling of mechanoelectrical transformations in dielectrics and the experimental studies showed $[8,9]$ that monitoring of the electromagnetic emission (EME) and acoustic emission (AE) of heterogeneous materials, including rocks, requires an analog-to-digital instrument to detect and record electromagnetic and acoustic signals in a frequency range of $(1 \div 100) \mathrm{kHz}$ in the internal memory. The input sensitivity of the analog amplifiers of electromagnetic signals is

*Corresponding author: besko48@tpu.ru 
about $10 \mu \mathrm{V}$, and that of acoustic signals is not more than $50 \mu \mathrm{V}$. Capacitive and inductive sensors are used to receive electromagnetic signals in laboratory and field conditions, and piezoelectric sensors are used to receive acoustic signals. The frequency ranges for electromagnetic emission detection were found in the study of rock block sizes conducted under the guidance of V.N. Oparin, the Corresponding Member of RAS6 in IM SB RAS [10]. Practical measurements showed the greatest size distribution of $L$ blocks in the range of $(2 \div 100) \mathrm{cm}$. Figure 1 shows the normalized distribution of the rock block sizes obtained through averaging with exposure window of $2 \cdot 10^{-2} \mathrm{~m}$ and scan step of $10^{-3} \mathrm{~m}$ reported in [10].

The ratio used for the fundamental wave frequency $f=V_{3} / 2 L$ at the average speed of sound in rocks $V_{3}=3000 \mathrm{~m} / \mathrm{s}$ indicates that the blocks of these sizes emit mostly electromagnetic signals (EMS) in the above frequency range. The bands of higher amplitude are observed in the frequency spectrum, namely in the range of $12-30 \mathrm{kHz}$ with central frequencies of $15-20 \mathrm{kHz}$, and in the range of 2-7 kHz. It should be noted that the EMS spectrum contains other frequencies, but they are of lower amplitudes. In addition, the laboratory studies showed that the EMS parameters depend on the characteristics of the excitation acoustic signal. This proves that acoustic signals generated by emerging and propagating cracks have a significant effect on the EMS frequency spectrum, which can also be observed in conditions of natural rock formation. Variations of the amplitude and duration of the excitation acoustic signal, and changed distance of the electromagnetic signal sensor from the radiating surface cause change in the EMS amplitude-frequency characteristics.

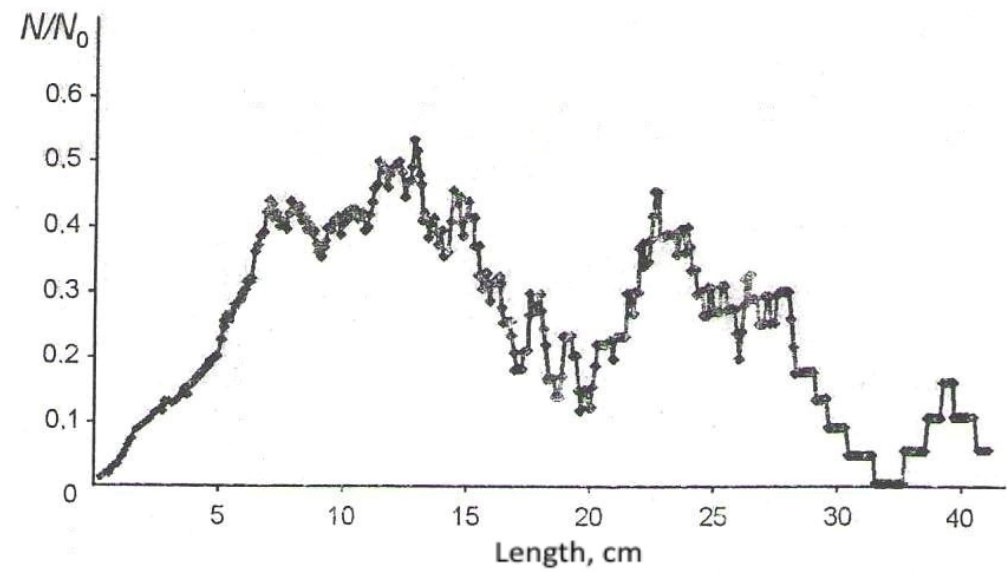

Figure 1. Normalized size distribution of the rock blocks [3].

\section{Recorder description}

The specified EMS frequency-response characteristics were used to design and manufacture the REMS-1 recorder and to perform its multiple testing in laboratory and field conditions. The REMS-1 recorder transforms electromagnetic signals via the capacity or induction receiver, then it transforms acoustic signals into analog signals with piezoelectric receiver, preprocesses and digitizes the signals, stores the obtained data in the internal memory and transmits the data arrays to PC [11-17]. To decrease the effect of electromagnetic interference, the analogue EMS reception was performed using a differential circuit $[18,19]$. To offset from industrial electromagnetic interference, signals below $1 \mathrm{kHz}$ were filtered but not recorded. The obtained values of the averaged EMS and 
AS amplitudes were digitized in the wideband of $1 \div 100 \mathrm{kHz}$, and the EMS were further filtered in three bands with center frequencies of 2.15 and $100 \mathrm{kHz}$. In order to reduce the data array and to improve its operational analysis, the EMS and AS amplitudes were averaged in a specified time interval of 1 or 5 seconds. These averaged EMS amplitude values $\mathrm{A}(t)$ showed changes in electromagnetic (EME) and acoustic (AE) emissions of heterogeneous materials and rocks under force or acoustic effects the time. These patterns are proportional to the change in the electric $\mathrm{E}(t)$ or magnetic $\mathrm{H}(t)$ components of the electromagnetic field in the wide-band $\left(\mathrm{F}_{\mathrm{WB}}\right)$ and in the bands with center frequencies of 2 $\mathrm{kHz}\left(\mathrm{F}_{2}\right), 15 \mathrm{kHz}\left(\mathrm{F}_{15}\right)$ and $100 \mathrm{kHz}\left(\mathrm{F}_{100}\right)$. During the development of the method the recorder received and recorded acoustic emission of the test objects to increase the reliability of detection of the destructive area formation. AS amplitudes indicate crack propagation in the test object during pre-destruction and destruction processes or acoustic exposure. In case of blasting with known parameters, the electromagnetic acoustic channels were calibrated according to the energy performance of the explosion. In addition, the number of EMS in the given averaging interval was found to change. As a result, the parameters of the change in the intensity of the electromagnetic signal pulse flux could be obtained.

The recorder consists of the units: data-collection unit (DCU); remote capacity (RCR) and induction (RIR) receivers connected in turn to the DCU differential input; acoustic receiver (AR); internal and auxiliary battery power supply (BDA) and power supply unit (PSU) to charge the batteries. The receivers and power supplies are connected to DCU via cable terminals. Figure 2 shows the block diagram of the recorder.

Electromagnetic signals are received by induction or capacity receivers, converted into electrical signals, amplified and fed to the inputs of differential amplifiers (D1, D2) [20, 21]. The signals from the differential amplifiers are the inputs of programmable switching and amplification unit (D3). The amplifier output is connected to three narrowband filters and one broadband filter with a variable gain of (D5 -7) and (D8). The amplified signals are fed to averaging unit $(\mathrm{D} 9 \div 12)$ and then to the inputs of ADC microcontroller (D20) [22, 23]. The electrical signals from variable-gain amplifier (D8) are the input of comparator (D14) with a programmable amplitude level. The comparator output is fed to counter (D15), and the signal from the counter is fed to microcontroller (D20).

Piezoelectric acoustic signals are received by the receiver, converted into electrical signals which are amplified and fed to the variable-gain amplifier input (D4). Electric signal D4 is fed to averaging unit (D13), and then to the input of ADC microcontroller (D20).

Microcontroller (D20) performs programmable digitizing of the analog signals in five channels, preprocessing of the digitized signals and stores the digital data in RAM (D18) and PROM FLASH (D16, D17). The microcontroller receives signals from real-time clock (D22) and keyboard signals $(\mathrm{S} 1 \div \mathrm{S} 6)$ through control logic (D29). Information on the device operation is provided on LCD (H1) [24]. The accumulated data arrays are displayed on PC through serial interfaces without optoisolator RS232 (D24) and optically isolated ones (D25 $\div 27$ ) RS485 (D28) $[25,26]$. The recorder is controlled by the programs stored in DCU unit. The operator uses a keyboard to choose the operating modes.

The stabilized voltage of $+5 \mathrm{~V}$ from regulator outputs (D21, D22) is supplied to the components of the electronic circuits, and voltage of $+3 \mathrm{~V}$ from $\mathrm{D} 23$ is used for LCD backlighting. The unregulated voltage of $+(6 \div 7) \mathrm{V}$ from the storage battery $\mathrm{E}_{1} \div \mathrm{E}_{6}$ is supplied to the stabilizer input. The battery is charged through V1 elements via the microcontroller.

The microprocessor data-collecting unit DCU (Figure 1) is controlled by the service program. The remote differential capacity and induction receivers, the piezoelectric sensor 
and supplementary external DC power supply, in case of long time operation, are connected through the terminals to the DCU.

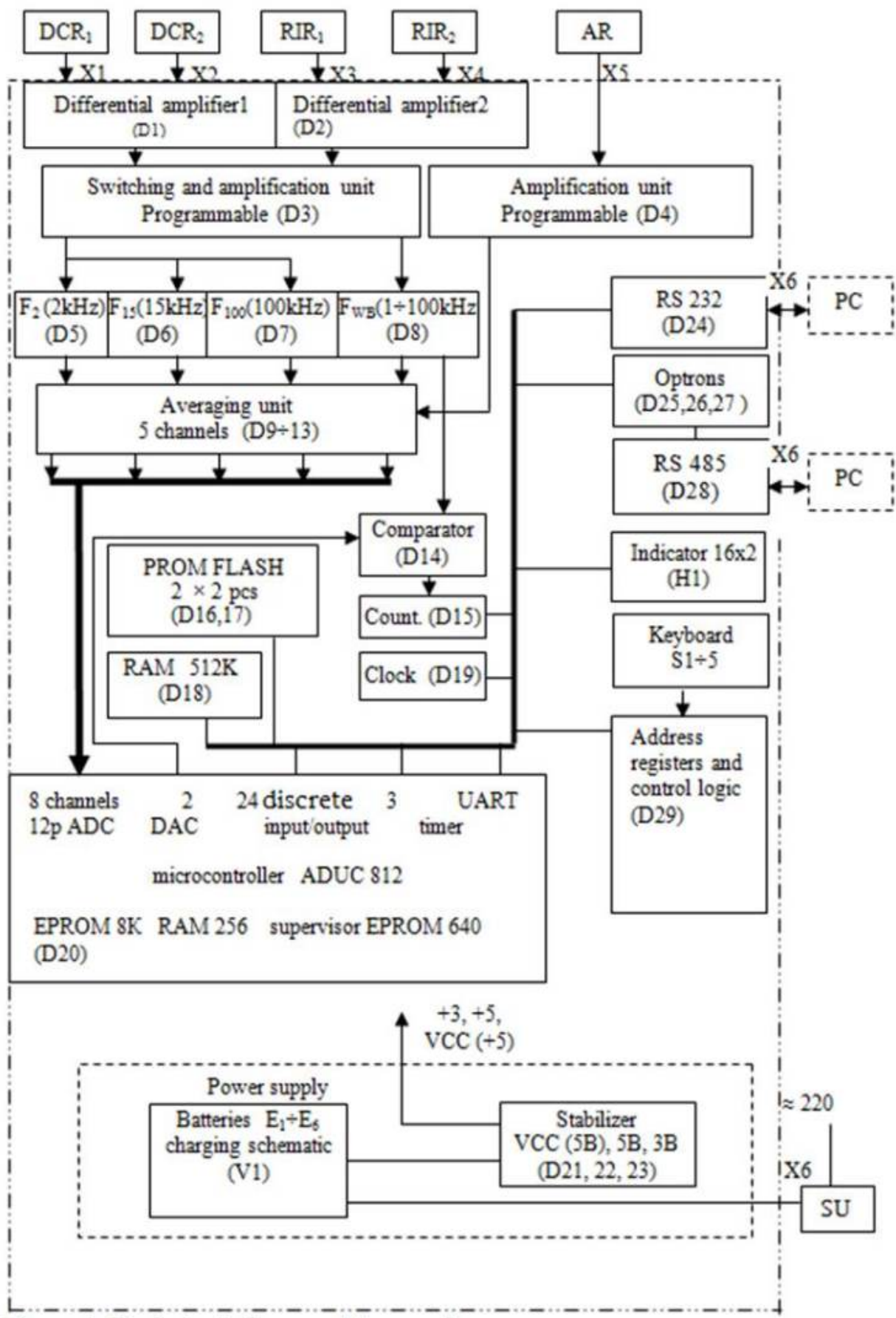

Figure 2. Block circuit diagram of the recorder. 
The microprocessor data-collecting unit provides:

- input and pre-processing of analog signals from electromagnetic and piezoelectric acoustic receivers;

- six channel digitizing the analog signals;

- pulse counting;

- accumulation and storage of data of up to $4 \mathrm{MB}$;

- quick viewing of the information on the LC display;

- the built-in battery operation for at least 40 hours;

- information storage in PC;

- battery charging.

The gain of differential amplifiers (D1, D2) is 4. Switching and amplification unit (D3) provides: programmable connecting to the RCR or RIR; setting the gain in the "menu" $(\times 1$, $\times 4, \times 8, \times 16$ ), which are displayed on the LCD and recorded in the measurement protocol when the electromagnetic channel amplification gain is set. Three narrow-band filters $(\mathrm{D} 5 \div 7)$ are tuned to the band center frequencies of $2 \mathrm{kHz}, 15 \mathrm{kHz}$ and $100 \mathrm{kHz}$, respectively, and are supplied with potentiometers to adjust the gain within $2 \div 32$. The averaging unit [21] supplied with five channels is based on chips of the full-wave rectifier of the average signal (D9 $\div 13$ ) with the time constant $\tau=1$ or 5 . Gain unit (D4) amplifies the electric signal of the acoustic receiver and provides the programmed gain $(\times 1, \times 2, \times 4, \times 8$, $\times 16, \times 32$ ). The gain value is chosen in the "menu" displayed on the LCD and recorded in the protocol. Comparator (D14) [21] extracts pulse signals and compares the signal amplitude from the amplifier output (D8) (channel without filtration and detection) with the programmed threshold value. If the signal exceeds this value, it generates positive pulse. "Counter" (D15) divides (into 16) a high-frequency signal from the comparator to count the number of pulses entering the microcontroller. Clock (D19) provides real time referencing. Serial interfaces without optoisolator RS232 (D24) and optically isolated interface (D25, D26, D27) RS485 (D28) provide connection to PC. Indicator (H1), a liquid-crystal indicator, has two lines and each line represents sixteen symbols. It displays the data on the parameters and operating modes chosen for unit operation in the form of digits or symbols and controls the input signal values. The keyboard S1 $\div$ S4 is used to control and choose the operating mode, and S5 provides power on/off mode.

Control registers and logic D29 selects the synchronization source, D33, 34 are the registers of the RAM address, D36 is a multiplexer control register, D37 is a unit control register, D38 is the decoder of unit selection, D39 is a keyboard case, D8 is optoisolator of external synchronization. The volume of the permanent storage unit PROM FLASH (D16, $\mathrm{D} 17)$ is $4 \mathrm{MB}$. It retains data when power is off and stores useful information. The volume of the random access memory RAM (D18) is $512 \mathrm{~KB}$. It records digital information for temporary storage with a maximum microcontroller digitization rate of $200 \mathrm{kHz}$. Microcontroller ADUC 812 (D20) has 8 channel 12 bit ADC, two DACs, three timer counters, parallel and serial ports for digital information input-output, 256 bytes data RAM, 640 bytes data EPROM and 8 Kbytes program EPROM. The microcontroller provides: program-controlled connection of the RCR or RIR receivers; selection of the channel gain; program-set signal level for the comparator; six channel digitization of the analog signals from the receivers; digital information storage in PROM; digitized signal preprocessing; communication with the operator through the keyboard and LCD; battery charging control. The components of the electronic circuits are powered from E1 $\div$ E6 batteries through stabilizers D21 $\div 23$. The storage battery is charged with the external power supply connected via controllable current regulator V1. DCU generates supply voltage for the receiver feed circuits, and provides spark protection of these circuits according to GOST 22782.5-78 "intrinsically safe electrical circuit". 
DCU software provides: selection of the RCR or RIR, gain factor, averaging time, comparation level; display of the set parameters, operation time, free memory and the values of the received signals on the LCD; mode setting (adjustment, monitoring, transmission of data arrays to the computer, battery charging). During monitoring, information is saved in the form of "pages" in the recorder memory in 256 averaged amplitudes of the $\mathrm{F}_{2}, \mathrm{~F}_{15}, \mathrm{~F}_{100}, \mathrm{~F}_{\mathrm{WB}}, \mathrm{AE}$ and EMS flux intensities. Each unit contains information on the set EME and $\mathrm{AE}$ parameters and start time. The maximum number of the stored monitoring data "pages" is 512. The PC provides a statistical analysis of the collected data. It is a general purpose computer, and it can be installed and used for short time operation in the mine or for permanent remote operation. DCU unit design meets the requirements of its tightness (IR53) and protection against electromagnetic interference and mechanical damage. The unit housing is made of a metal box with sealing on the side of the connectors, and on the keyboard and indicator cover. Unused connectors must be closed off [20]. The front surface of the DCU contains a control panel to set the adjustment mode, to monitor and transmit data arrays to the $\mathrm{PC}$ and to charge the batteries. The LCD indicates the settings in the recorder menu in the monitoring mode, transmission of data arrays to the PC, inbuilt battery charging and running EME and $\mathrm{AE}$ characteristics. The unit can perform self-testing.

\section{Application of the recorder in natural conditions by the example of the Tashtagol Mine}

The results of the laboratory studies of the effect of rock contacts on EMS parameters were used to develop a passive method to control SSS changes in the rock mass in the Tashtagol mine.

The observed area was picketed (Figure 3), the sections being spaced at a distance of 3 $\mathrm{m}$. The geology of the sections from 1 to 5 pickets was represented by magnetite. In the area of 5-6 pickets, a dike-formed bulk inclusion was found to contact with skarns on its opposite side.

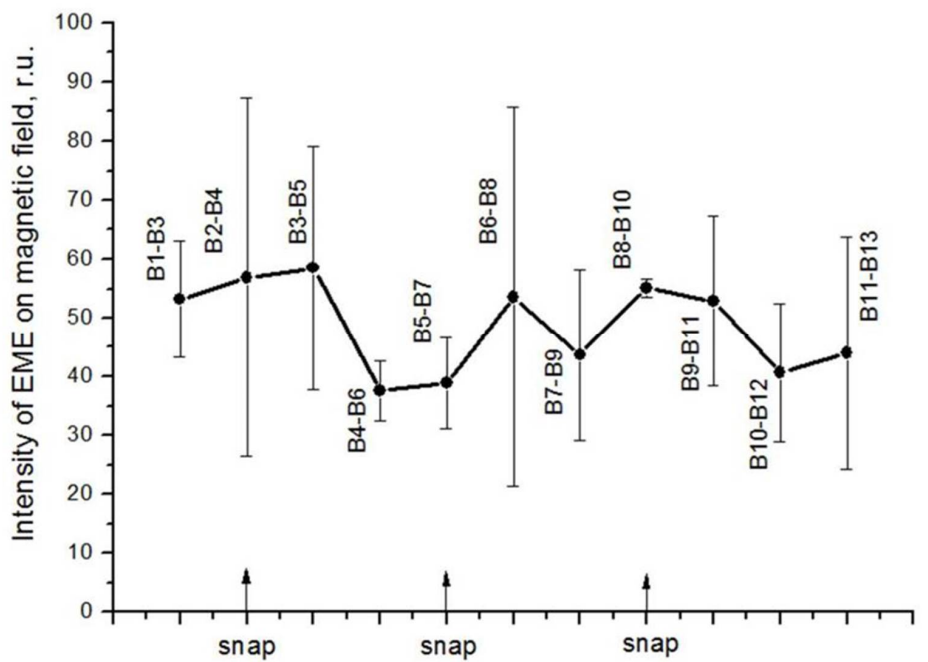

Figure 3. Change in the EME intensity during profiling in ort 2 level -210 in the Tashtagol mine.

In the 9 picket section, a tectonic crack was observed. The studies were conducted by the profiling method using the REMS complex supplied with downhole inductive sensors. The rock pressure geodynamic manifestations detected in this section were followed by a sound effect in the form of clicks. Figure 3 shows the average EME flux intensity in the 
magnetic component of the electromagnetic field during profiling ort 2 level -210 and the variance in each measurement. The change in the EME flux intensity is detected in the region of ore-dike contact (picket B4-B6), and dike-skarn contact (picket B6-B9). A sharp change in the EME is also observed in the B10 picket section. This area contains tectonic fractures. Earlier studies found that a prediction sign of unstable rock state is not only abnormal change in EME flux intensity, but increase in its dispersion as well.

The studies revealed the greatest variance in EME flux intensity in the above picketed sections. The arrows along the horizontal line show the pickets, where sound effects ("clicks") of rock pressure geodynamic manifestations were recorded. During the EME intensity measurements, significant increase in the electromagnetic radiation intensity dispersion was distinctly recorded before "clicks". After the "click", the EME dispersion sharply reduced to $(10-15) \%$. In addition, it was found that the longer the period of increased EME intensity dispersion, the more powerful the geodynamic effect in the rock.

This confirms the fact that the change in the rock SSS is followed by the change in the electromagnetic field that is manifested by abnormal changes in the EME intensity and its increased dispersion. The same section ort 2 level -210 was taken to study EMS parameters for testing fracturing of rocks of different conductive properties.

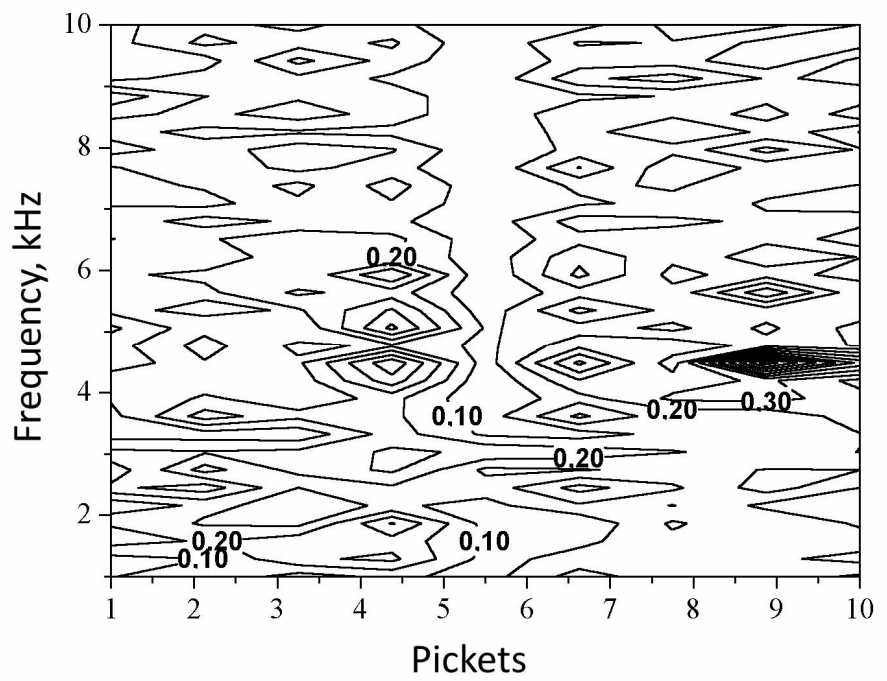

Figure 4. Distribution of isolines of amplitude-frequency electromagnetic signal parameters during subsurface profiling.

The pit edge was exposed to dynamic effects and the EMS was recorded. The recorded electromagnetic responses were analyzed and the amplitude-frequency characteristics were calculated using fast Fourier transform to construct isolines. It should be noted that the dynamic effect on the rock causes electromagnetic responses recorded at frequencies up to $10 \mathrm{kHz}$. Figure 4 shows the isolines of the EMS amplitude-frequency characteristics. The abscissa indicates the picket numbers, the ordinate shows the EMS frequencies, and the map demonstrates the spectral frequency band amplitudes. The Figure shows a distinct contact boundary between the rock made of ore and dikes on the one side and that formed of dikes and skarns on the other side starting from frequency of $2.5-3 \mathrm{kHz}$. In the 9 picket section at the point of the tectonic crack emergence, the frequency achieves its maximum of $4 \mathrm{kHz}$.

The EME observed for contacts of the rocks can be effectively used to monitor the changes in the rock SSS during and after explosion. Figure 5 shows the results of the EME 
measurement within 5 minutes after blasing of about 300 tons in 11 block between the -210 and $-280 \mathrm{~m}$ levels in the Tashtagol mine.

Figure 5 shows the electromagnetic emission variations that indicate the response of the rock to blasting and relaxation of its excited state. The EME variations reveal significant difference in the times of the processes occurring in the rock during and after blasting.

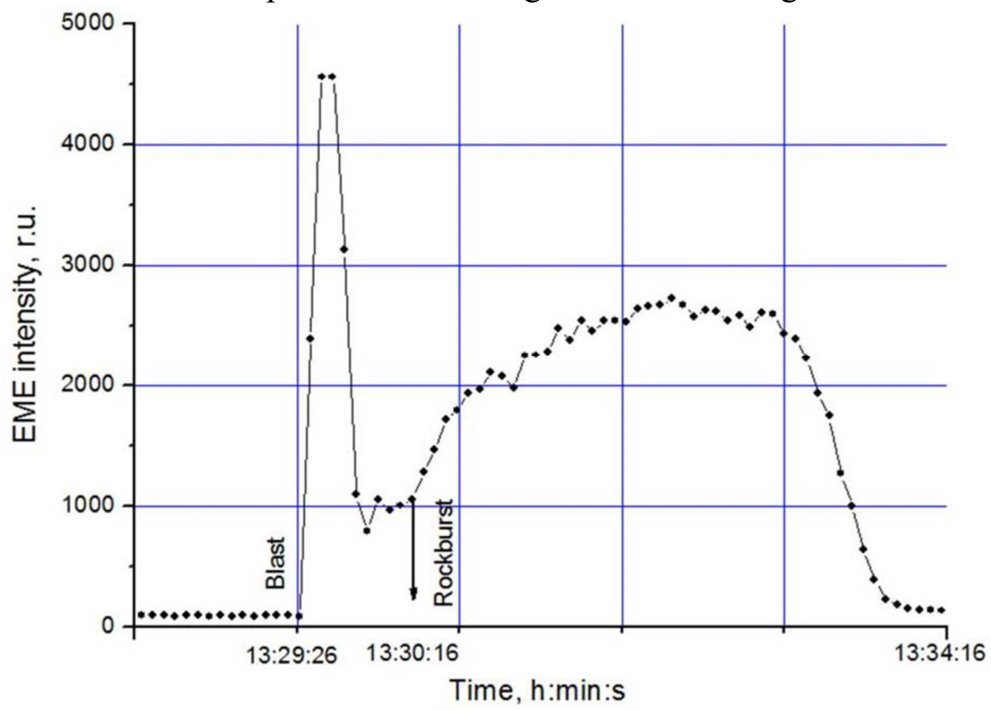

Figure 5. Change in the EME intensity during blasting and subsequent rock burst.

During blasting, the increased EME lasts $15 \mathrm{~s}$. After the rockburst, the rock respond duration is more than 4 minutes, and the seismic station in the Tashtagol mine recorded a great number of geodynamic manifestations of different energy levels in the explosion zone. When the EME intensity dropped to its explosive level and then after 30 minutes, it started to increase up to the values two-fold exceeding the maximum intensity after the rock burst. The increased EME values were observed over 17 hours, and then the intensity dropped to a certain level. At this period of time, the seismic activity in the mine field was observed to decrease.

\section{Conclusions}

Thus, an analog-to-digital recorder of electromagnetic and acoustic emissions was developed and designed for laboratory and field operation to monitor electromagnetic and acoustic signals under changed stress-strain state of heterogeneous materials and rocks. The analog amplifier input sensitivity of electromagnetic signals in 4 channels is $10 \mu \mathrm{V}$, that of the electromagnetic signal intensity is $10 \mu \mathrm{V}$, and the acoustic signal sensitivity is $50 \mu \mathrm{V}$. The operating frequency range of recording is $(1 \div 100) \mathrm{kHz}$. The averaging of the electromagnetic and acoustic signal amplitudes is performed within 1 or 5 seconds. The data obtained for electromagnetic and acoustic emissions is recorded in digital format and stored in the recorder internal memory. The recorder battery life time is 7 days.

The field studies in the Tashtagol Mine showed that the changes in the EMS amplitudefrequency parameters can be used to evaluate the structural disturbance in mines formed of rocks which differ in their electrical properties. Measurements of the electromagnetic signals intensity allow monitoring of changes in the rock stress-strain state during and after blasting, and during different geodynamic processes. This monitoring technique can be 
advantageously used in places where outcropping dikes and veins extend into the area of geodynamics processes in the rock.

\section{Acknowledgments}

This work was supported in part by the Ministry of Education and Science of the Russian Federation under the State Research Project and by Russian Foundation for Basic Research Grant No. 14-08-00395.

\section{References}

[1] Y. Mori, Y. Obata and J. Sikula, J. Acoustic Emission 27, 157 (2009)

[2] P. Koktavy, J. Pavelka and J. Sikula, Meas. Sci. Technol. 15, 973 (2004) doi: 10.1088/0957-0233/15/5/028

[3] V. Frid, A. Rabinovitch and D. Bahat, J.Phys. D: Appl. Phys. 36, 1620 (2003) doi: $10.1088 / 0022-3727 / 36 / 13 / 330$

[4] A. Pralat, S. Wójtowicz, Acta Geodyn. Geomater. 1, 111, (2004)

[5] J. Sobotka, Acta Geoph. 57, 247 (2009) doi: 10.2478/s11600-008-0072-4

[6] H. Kobayashi, K.Horikawa, K.Ogawa, and K.Watanabe, Phil. Trans. R. Soc. 372, 20130292 (2014) doi: 10.1098/rsta.2013.0292

[7] P. Koktavy, Meas. Sci. Technol. 20, $015704 \quad$ (2009) doi: 10.1088/0957-0233/20/1/015704

[8] A.A. Bespal'ko, R.M. Gol'd, L.V. Yavorovich, D.I. Datsko, J. Min. Sci. 39,12 (2003) doi: 10.1023/B:JOMI.0000008455.54729.30

[9] A.A. Bespal'ko, L.V. Yavorovich, P.I. Fedotov, J. Min. Sci. 43,472 (2007) doi: 10.1007/s10913-007-0049-8

[10] V.N. Oparin, V.F. Yushkin, A.A. Akinin, E.G. Balmashnova, FTPRPI (5), 34 (1998)

[11] I.P. Golyamin, Ul'trazvuk malenkaya ehnciklopediya (Sovetskaya ehnciklopediya, Moskau, 1979) (in Russian)

[12] K.S. Petrov, Radiomaterialy radiokomponenty i ehlektronika (Piter, Spb.,2003) (in Russian)

[13] E. Kikuchi, Ul'trazvukovye preobrazovateli (Mir, Moscow, 1972) (in Russian)

[14] M.V. Korolyev, Defektoskopiya (4), 65, (1973) (in Russian)

[15] I. Plotnikova, L. Redko, O. Titova, O. Chaykovskaya, IOP Conf. Ser.: Mater. Sci. Eng. 132, 012023 (2016) doi: 10.1088/1757-899X/132/1/012023

[16] S. Obukhov, I. Plotnikov, M. Kryuchkova, IOP Conf. Ser.: Mater. Sci. Eng. 132, 012017 (2016) doi: 10.1088/1757-899X/132/1/012017

[17] O.V. Galtseva, S.V. Bordunov, IOP Conf. Ser.: Mater. Sci. Eng. 81, 012062 (2015) doi: 10.1088/1757-899X/81/1/012062

[18] A.G. Alekseenko, Osnovy mikroskhemotekhnik (Yunimedistail, Moscow, 2002) (in Russian)

[19] U. Titce, K. Shenk, Poluprovodnikovaya skhemotekhnika (Mir, Moscow,1982) (in Russian)

[20] M.A. Kireev, Sovremennye zarubezhnye mikroskhemy - usiliteli zvukovoj chastoty spravochnik (Goryachaya liniya, Moscow, 2004) (in Russian)

[21] Operacionnye usiliteli i komparatory: spravochnik (Dodeka-XXI, Moskow, 2002) (in Russian)

[22] Specifikaciya ADuC812 8-kanalnyj precizionnyj 12 razryadnyj ACP so vstroennym mikroprocessorom i FLASH EHRPZU (Spb.: AVTEKS. http://www.autex.spb.ru) (in Russian) 
[23] ADuC812: MicroConverter, Multichannel 12-Bit ADC with Embedded Flash MCU Data Sheet (Rev E, 04/2003) URL: http://www.analog.com LCD screen PC1602 URL: http://www.powertipusa.com

[24] Optocouplers 6N137 URL:http://fairchildsemi.com

[25] V.S. Valenko, Poluprovodnikovye pribory i osnovy skhemotekhniki ehlektronnyh ustrojstv (Dodeka-XXI, Moskow, 2001) (in Russian)

[26] L. Ruzziconi, S. Lenci , M.I. Younis, MATEC Web of Conferences 16, 04001 (2014) doi: 10.1051/ matecconf/2014 1604001 